\title{
Stabilization of Electric-Arc Furnace Dust in Concrete
}

\author{
Carlos Alberto Caldas de Souza*, Alexandre Teixeira Machado,
}

Luiz Rogério Pinho de Andrade Lima, Roberto Jorge Câmara Cardoso

\author{
Department of Materials Science and Technology, Federal University of Bahia-UFBA, \\ Rua Aristides Novis, 2, CEP 40210-630, Salvador, BA, Brazil
}

Received: August 9, 2010; Revised: November 15, 2010

\begin{abstract}
Electric-arc furnace dust (EAFD) is a by-product of steel production and recycling. This fine-grained material contains high amounts of zinc and iron as well as significant amounts of potentially toxic elements such as lead, cadmium and chromium. Therefore, the treatment and stabilization of this industrial residue is necessary. Concrete is a well-known suitable environment for stabilization/solidification of materials which have leachable elements in need of fixation. The effect of the EAFD content on the mechanical and chemical performance of Portland cement concrete is investigated in this paper. The effect of the EAFD content on the setting time of cement slurry was also analyzed. The axial compressive strength of the concrete samples increases with the EAFD addition in the range of 10 to $20 \mathrm{wt}$. (\%) EAFD; also the tensile strength increases with the EAFD addition. An increase in EAFD content significantly increases the setting time of the concrete. The acetic acid leaching and water solubilization tests indicate low mobility of the potentially toxic elements from the EAFD concrete composite. The results of the immersion tests show that the addition of EAFD to the concrete seems to reduce chloride penetration, which may help prevent pitting corrosion in reinforced concrete.
\end{abstract}

Keywords: electric-arc furnace dust, leaching, cement matrix, chloride, diffusion

\section{Introduction}

Electric-arc furnace dust (EAFD) is by-product of steel production and recycling and it is widely reported that about $15-20 \mathrm{~kg}$ of dust is produced for each ton of steel produced ${ }^{1}$. It is a complex, fine-grained, high-density material containing high amounts of zinc and iron, and significant amounts of calcium, manganese, magnesium, lead, and chromium ${ }^{1,2,3}$. The phase identification of the EAFD samples indicates the presence of complex minerals such franklinite $\left(\mathrm{ZnFe}_{2} \mathrm{O}_{4}\right)$, magnetite $\left(\mathrm{Fe}_{3} \mathrm{O}_{4}\right)$, magnesium-ferrite $\left(\mathrm{MgFe}_{2} \mathrm{O}_{4}\right)$, chromite $\left(\mathrm{FeCr}_{2} \mathrm{O}_{4}\right)$, calcium-magnetite $\left(\mathrm{Ca}_{0.15} \mathrm{Fe}_{285} \mathrm{O}_{4}\right)$, periclase $(\mathrm{MgO})$, manganese oxide $\left(\mathrm{Mn}_{3} \mathrm{O}_{4}\right)$, quartz $\left(\mathrm{SiO}_{2}\right)$ and zincite $(\mathrm{ZnO})^{3}$. For various reasons, electric-arc furnace technology is currently used in most global steel production worldwide. EAFD is an industrail residue in need of stabilization and concete is known to be a suitable ${ }^{4-8}$. Concrete is a well-known suitable environment for stabilization/solidification, which is favorable for some materials that have leachable elements and need fixation. Moreover, the properties of the concrete may be enhanced due to the zinc and pozzolanic compounds present in the waste. Therefore, the use of EAFD in concrete is an interesting option.

The effects of a small amount of EAFD on the properties of concrete have been investigated ${ }^{4,7,8,9}$. The dust has been used as a replacement for cement by mass in 2 and 3\%, and the results obtained indicate that the EAFD retards the setting time and enhances the compressive and shearing strengths as well as resistance to abrasion.

Some environmental agents can induce concrete degradation, which significantly impact the performance of concrete structures. Corrosion of reinforced bars can cause failure and increase costs as support and repair are needed. The pitting corrosion in the reinforced bars caused by the penetration of chloride ion is a serious concrete degradation problem as pitting acts as a point of stress concentration, which can lead to a significant decrease in mechanical strength.
The radial penetration of chloride in a circular satured cylindrical samples can be evaluated using the Fick's second law of diffusion in cylindrical coordinates. Assuming that the chloride concentration is initially uniform throughout the cylinder, the surface concentration is constant and using the non-steady diffusion equation in cylindrical coordinates as the governing equation of the chloride penetration ${ }^{10}$ :

$$
\begin{aligned}
& \frac{\partial C}{\partial t}=\frac{1}{r} \frac{\partial}{\partial r}\left(r D_{a p} \frac{\partial C}{\partial r}\right) \\
& C(r, t)=C_{0}, \quad r=a, \quad t \geq 0 \\
& C(r, t)=C_{1}, \quad 0<r<a, \quad t=0 \\
& \frac{\partial C(r, t)}{\partial r}=0, \quad r=0, \quad t \geq 0
\end{aligned}
$$

where, $C$ is the chlorine concentration in the cylinder, $t$ is the time, $r$ the radial position inside the cylinder, $D_{a p}$ the apparent diffusivity of the chloride in the cylinder, $C_{0}$ the chloride concentration at the cylinder surface, and $C_{1}$ the initial chloride concentration throughout the cylinder, and a is the cylinder radius. In the case of no initial chloride in the cylinder, the analytical solution of the transient chloride profile is given by ${ }^{10}$ :

$$
C(r, t)=C_{0}\left[1-\frac{2}{a} \sum_{n=1}^{\infty} \frac{e^{-D_{a p} \alpha_{n}^{2} t} J_{0}\left(r \alpha_{n}\right)}{\alpha_{n} J_{1}\left(a \alpha_{n}\right)}\right]
$$

where, $J_{0}$ and $J_{1}$ are the Bessel functions of the first kind and order zero and one, respectively and $\alpha_{n}$ are the positive roots of the equation:

$$
J_{0}\left(a \alpha_{n}\right)=0
$$


Equation 3 gives the chloride penetration curves that are initially sharp and becomes smooth with the time by increasing the concentration at the cylinder center line. Figure $1 \mathrm{a}, 1 \mathrm{~b}$ and $1 \mathrm{c}$ show the simulated profiles using typical apparent diffusivity coefficient for the chloride in concrete ${ }^{11}$. One remark that in short term of exposures to chloride, below two months, the penetration profiles can be already well developed.

The experimental effect of the EAFD content on the concrete resistance to chloride penetration has not been studied yet, and this is one of the objectives of this paper. In addition to the mechanical properties, the solubilization of the potentially toxic elements of EAFD is addressed.

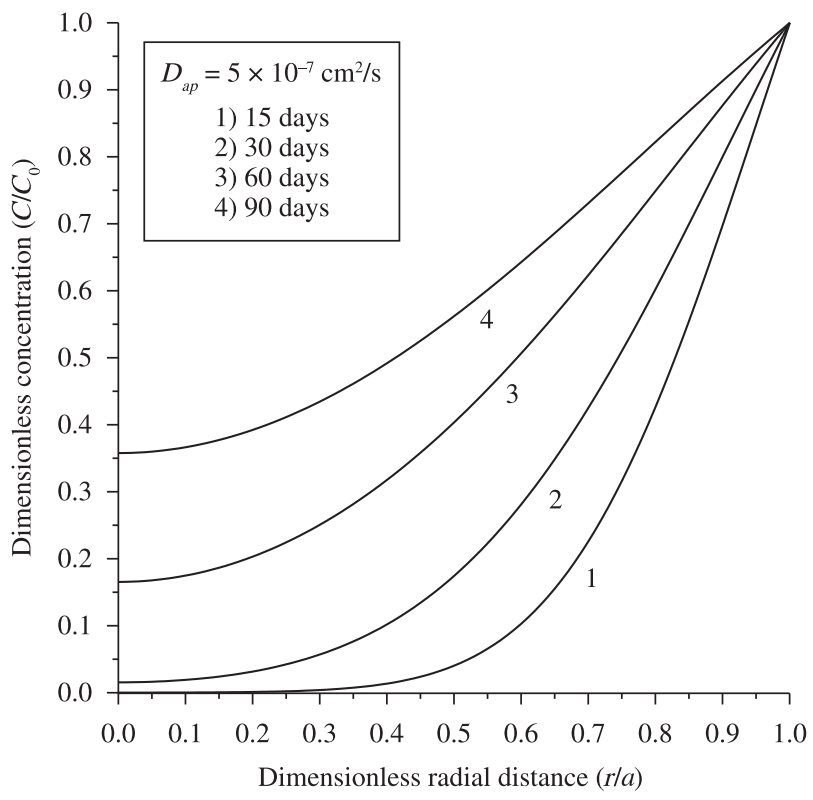

(a)

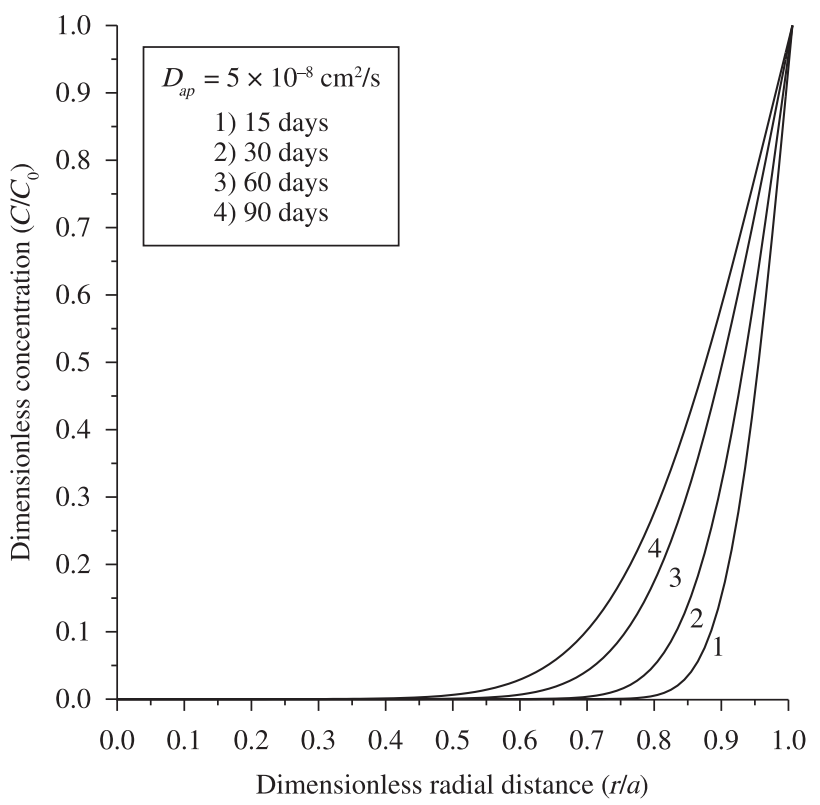

(c)

Figure 1. Simulated chloride concentrations distribution in the cylinder for short term exposure to chloride and typical values of apparent diffusivity (using Equation 3): a) $D_{a p}=5 \times 10^{-7} \mathrm{~cm}^{2} / \mathrm{s}$; b) $D_{a p}=1 \times 10^{-7} \mathrm{~cm}^{2} / \mathrm{s}$; and c) $D_{a p}=5 \times 10^{-8} \mathrm{~cm}^{2} / \mathrm{s}$.
The paper is organized as follows. The second section presents the experimental procedure, the third section presents the results and discussion, and the fourth section presents the conclusions.

\section{Experimental Procedure}

\subsection{Materials}

A Portland cement (CP-F 32) was used in this study. Washed sand was used as fine aggregate, while the coarse aggregate was crushed aggregates. They were used in all the blends studied. The apparent density, grain density and large size particles of the aggregates are shown in Table 1. It can be noted that the apparent density is very

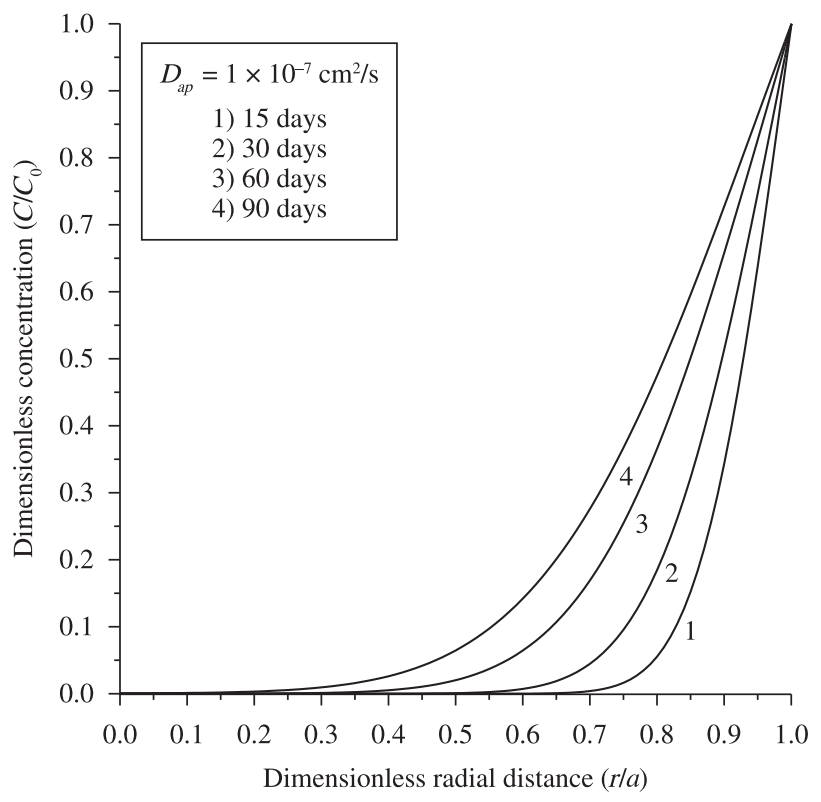

(b) 
close, despite the fact that the grain density is not the same. The ratio between the large particles is about 20 for the finer aggregate and coarse aggregate.

The EAFD was provided by a steelmaking plant located in Bahia (Brazil) which is fed with hematite pellets produced in Minas Gerais (Brazil) and with iron scrap. The main components of the EAFD evaluated by atomic absorption spectroscopy are presented in Table 2 . Of note are the large iron and zinc contents that characterize this material. The density of the EAFD is $4.08{\mathrm{~g} . \mathrm{cm}^{-3}}^{-3}$ and the specific surface is $7310 \mathrm{~cm}^{2} \cdot \mathrm{g}^{-1}$. The EAFD is a highly dense material, which is compatible with the chemical and mineralogical content ${ }^{1,2,3}$. Figure 2 presents the EAFD size distribution, estimated by free settling and density evaluation in a graduated cylinder. This material is much finer with $\mathrm{a} \mathrm{d}_{50}$ of about $8.5 \mu \mathrm{m}$. The microscopic evaluation of the EAFD samples in secondary electrons was performed using a

Table 1. Physical properties of the aggregates.

\begin{tabular}{lccc}
\hline Aggregate & $\begin{array}{c}\text { Apparent } \\
\text { density }\left(\mathrm{g} . \mathrm{cm}^{-3}\right)\end{array}$ & $\begin{array}{c}\text { Grain density } \\
\left(\mathrm{g} . \mathrm{cm}^{-3}\right)\end{array}$ & $\begin{array}{c}\text { Maximum } \\
\text { particle size } \\
(\mathrm{mm})\end{array}$ \\
\hline Fine aggregate & 1.55 & 2.62 & 0.6 \\
Coarse aggregate & 1.54 & 2.74 & 19 \\
\hline
\end{tabular}

Table 2. Chemical composition of EAFD.

\begin{tabular}{lcc}
\hline \multicolumn{1}{c}{ Element } & Unit & Content \\
\hline Iron & $\%$ & 35.89 \\
Zinc & $\%$ & 10.76 \\
Lead & $\%$ & 0.9876 \\
Aluminum & $\%$ & 0.7295 \\
Copper & mg.kg-1 & 689.9 \\
Cadmium & $\mathrm{mg} \cdot \mathrm{kg}^{-1}$ & 193.9 \\
Barium & $\mathrm{mg} \cdot \mathrm{kg}^{-1}$ & 164.7 \\
Nickel & $\mathrm{mg} \cdot \mathrm{kg}^{-1}$ & 107.6 \\
Silver & $\mathrm{mg} \cdot \mathrm{kg}^{-1}$ & 35.13 \\
Chromium & $\mathrm{mg} \cdot \mathrm{kg}^{-1}$ & 29.22 \\
\hline
\end{tabular}
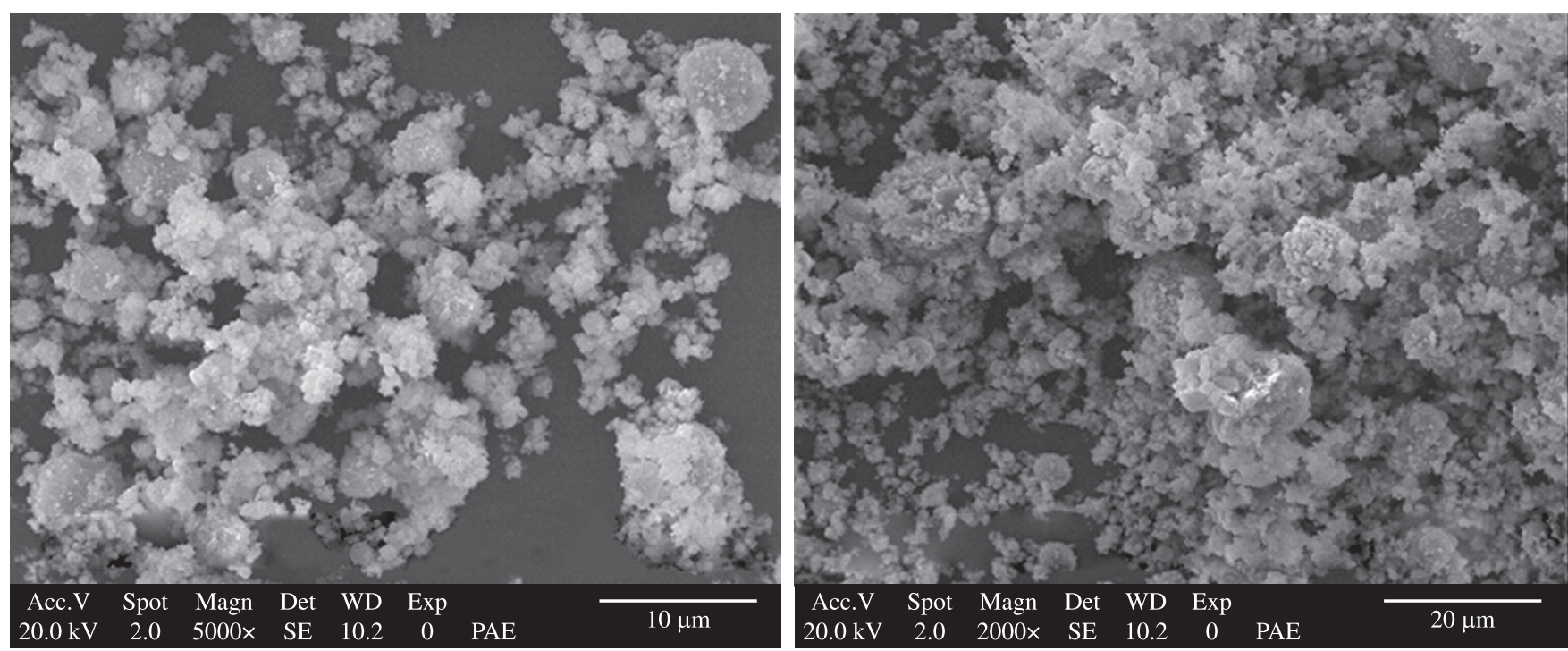

scanning electron microscope Philips model XL-30. Figure 3 shows two images of the EAFD particles. The fine particles can be observed and some aggregation between the particles and an almost spherical morphology of the particles.

\subsection{Preparation of the concrete samples}

In order to evaluate the effect of the EAFD on the concrete characteristics, concrete samples containing different EAFD contents in relation to cement (EAFD 0.0 wt. (\%); EAFD 10 wt. (\%); EAFD 15 wt. (\%); and EAFD 20 wt. (\%)) were prepared. Table 3 summarizes the composition of the blends; note that the water-cement ratio is 0.54 . The samples were cast in a cylindrical mould of $100 \mathrm{~mm}$ in diameter and $200 \mathrm{~mm}$ in height. After drying at $25{ }^{\circ} \mathrm{C}$, the specimens were removed from their moulds and wet-cured for 28 day.

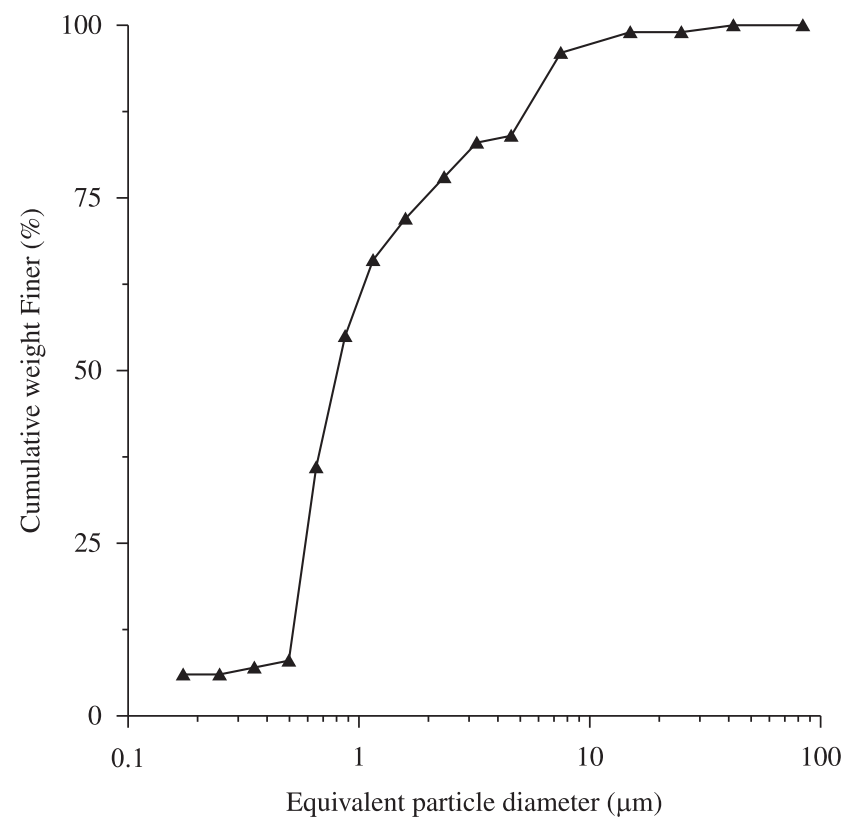

Figure 2. EAFD size distribution.

Figure 3. Secondary electrons SEM image of the EAFD. 


\subsection{Test methods}

The effect of EAFD addition on the axial compressive strength and the tensile strength by radial compression of the concrete samples was evaluated using the tensile strength test ${ }^{12}$, as shown in Figure 4. Each test was repeated three times for each condition. The compressive load was applied using a $300 \mathrm{kN}$ compression machine, CWK model, at a rate of $0.3 \mathrm{Nmm}$.s. The tensile strength, obtained by radial compression, was calculated using the equation:

$$
\sigma=\frac{2 P}{\pi D t}
$$

where, $\sigma$ is the maximum tensile stress in the perpendicular direction to the applied load, $P$ is the rupture load applied to the radial direction of the sample, $D$ is the diameter of the cylindrical sample, and $t$ is the length of the cylindrical sample.

Table 3. Blend ratio of concrete (in weight basis).

\begin{tabular}{cccc}
\hline Cement & $\begin{array}{c}\text { Fine aggregate } \\
(\text { sand })\end{array}$ & $\begin{array}{c}\text { Coarse } \\
\text { aggregate }\end{array}$ & Water \\
\hline 1.00 & 2.01 & 3.38 & 0.54 \\
\hline
\end{tabular}
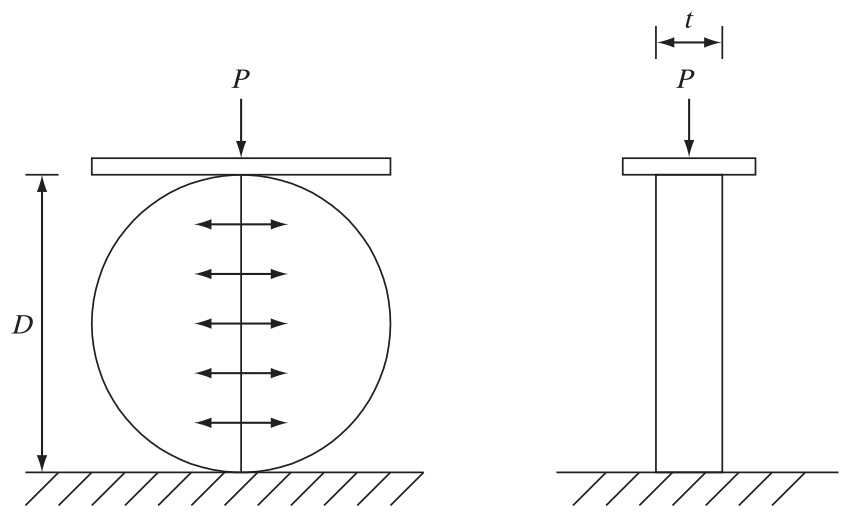

Figure 4. Schematics of the Brazilian tensile strength test.

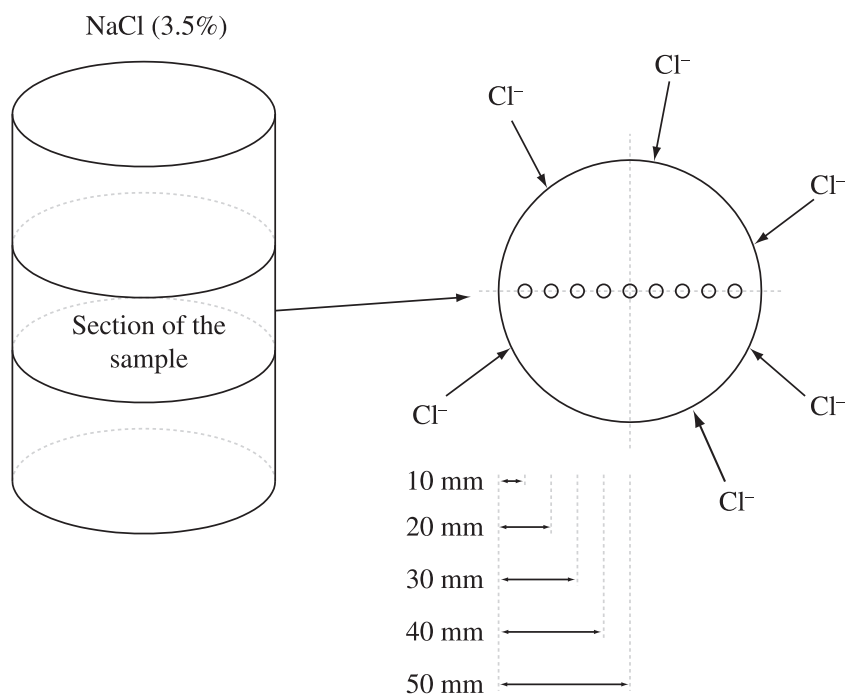

Figure 5. Schematic representation of the method used for the immersion of concrete specimens.
To perform the chloride penetration experiments, the concrete samples were fully immersed in the $3.5 \mathrm{wt}$. (\%) sodium chloride solution. After 15, 30 or 60 days, samples of the axial direction of the concrete cylinders were extracted by drilling at 10, 20,30, 40, and $50 \mathrm{~mm}$ from surface (Figure 5). After drying the samples in an oven, these powdered samples were mixed with a hot water solution and filtered. The liquid phase was collected in the volumetric flask and titred with $0.01017 \mathrm{~N}$ silver nitrate solutions using a potassium chromate solution $0.05 \mathrm{~N}$ as indicator (the classical Mohr method) ${ }^{13}$. The salt content is given as a percent of chloride per cement weight. Each test was repeated three times for each condition.

The leaching and solubilization tests were carried out with concrete samples containing different EAFD contents (with regard to cement weight). These tests were carried out in accordance with the Brazilian Standard ${ }^{14,15}$, which are based on the EPA method used for waste classification.

The setting time indicated the time necessary to begin and finish the hardening of the cement paste, and the tests were carried out according to the Brazilian Standard NBR NMS65/2003 ${ }^{16}$ the setting time was evaluated by measuring the penetration of a needle into the cement paste until it reaches a vary small value.

\section{Results and Discussion}

\subsection{Mechanical strength}

The effect of EAFD addition on the axial compressive strength and on the tensile strength of the concrete samples after 28 days curing is reported in Figures 6 and 7, respectively. The results show that the increase in the axial compressive strength with EAFD addition is in accordance with previous work reported in the literature ${ }^{4}$, which also verified the increase in the compressive strength of concrete containing a small addition of EAFD ( 2 and 3 wt. (\%)), attributable to its pozzolanic characteristics ${ }^{4}$.

Furthermore, as regards the tensile strength values (Figure 7), the samples with EAFD present similar or slightly better strength than traditional concrete, despite this increase in strength being lower than

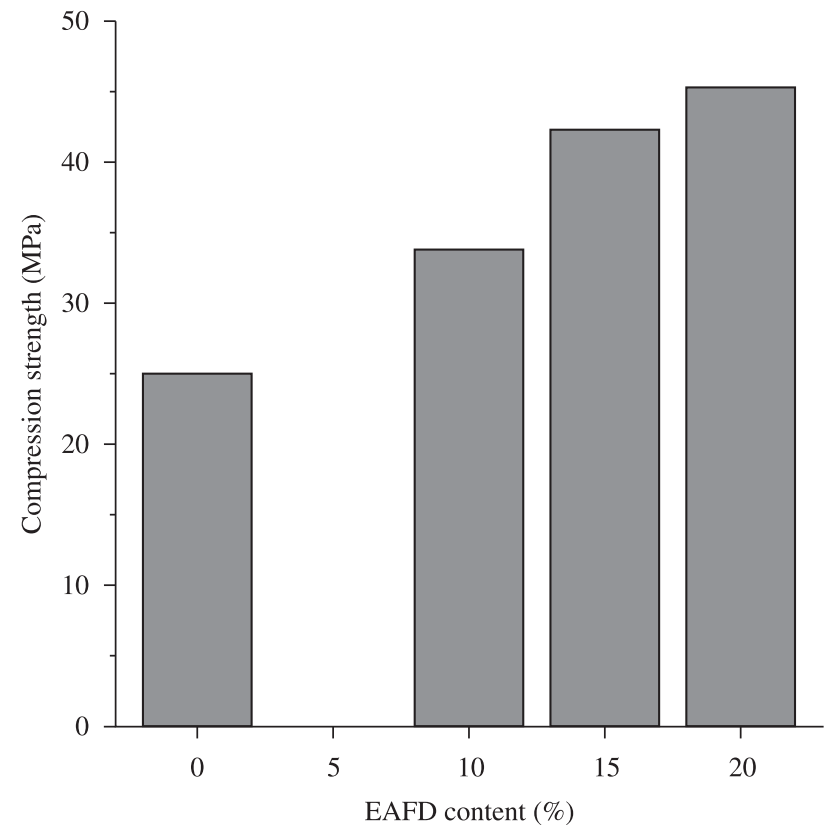

Figure 6. Concrete sample axial compression strength at 28 days. 


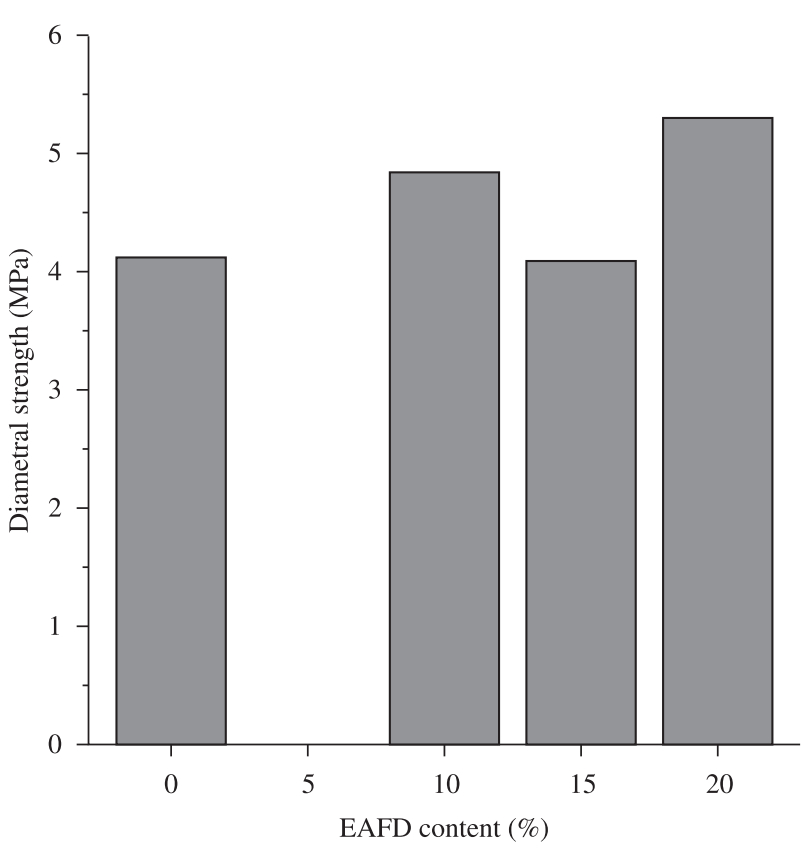

Figure 7. Concrete sample diametral strength after 28 days.

that obtained in compressive strength measurements. The apparent lower value found for sample with $15 \mathrm{wt}$. (\%) of EAFD, contrasting with samples content 10 and 20 wt. (\%) of EAFD, is within the experimental error of the method. It is possible that the effect of the addition of EAFD on the increase in concrete strength is related to the characteristics of the fine materials in the EAFD. The addition of such a fine material in the concrete can increase its apparent uniformity and homogeneity and density; moreover, it seems that the addition of this fine material reduces the concrete porosity, which in turn increases the useful area. This hypothesis is consistent with the experimental results that show a decreased of water absorption in concrete $^{17}$ samples due to EADF addition, indicating therefore the increase in density with the presence of this material.

\subsection{Setting time of Portland cement concrete composite}

A strong impact of EAFD on the setting time of concrete was observed: the samples required more than 48 hours to harden completely (Figure 8). Then, the "Vicat method" test was carried out with cement paste in order to verify this performance. The results confirmed that the addition of EAFD to the cement paste increases the setting time significantly, also observed in prior work ${ }^{4}$.

The delay in the setting time of the samples with EAFD addition could be related to the $\mathrm{Zn}$ content in the EAFD chemical composition. Initially present in the EAFD as oxide $(\mathrm{ZnO})$, the $\mathrm{Zn}$ changes into amorphous hydroxide, $\mathrm{Zn}(\mathrm{OH})_{2}$, which forms a protective coating on the surface of anhydrous cement grains ${ }^{18,19}$. This coating formation delays cement hydration, mainly the $\mathrm{C}_{3} \mathrm{~S}$ phase, and after this delay high $\mathrm{Ca}^{2+}$ and $\mathrm{OH}^{-}$concentrations enable the zinc hydroxide to transform into zinc calcium hydroxide, which is a crystalline compound. After that the hydration process starts again ${ }^{19}$.

\subsection{Leaching tests}

Tables 4 and 5 show the results of the acetic acid leaching and water solubilization tests carried out with concrete samples containing EAFD. In these tables the chemical element values obtained from the concrete samples and the limit values determined by the Brazilian

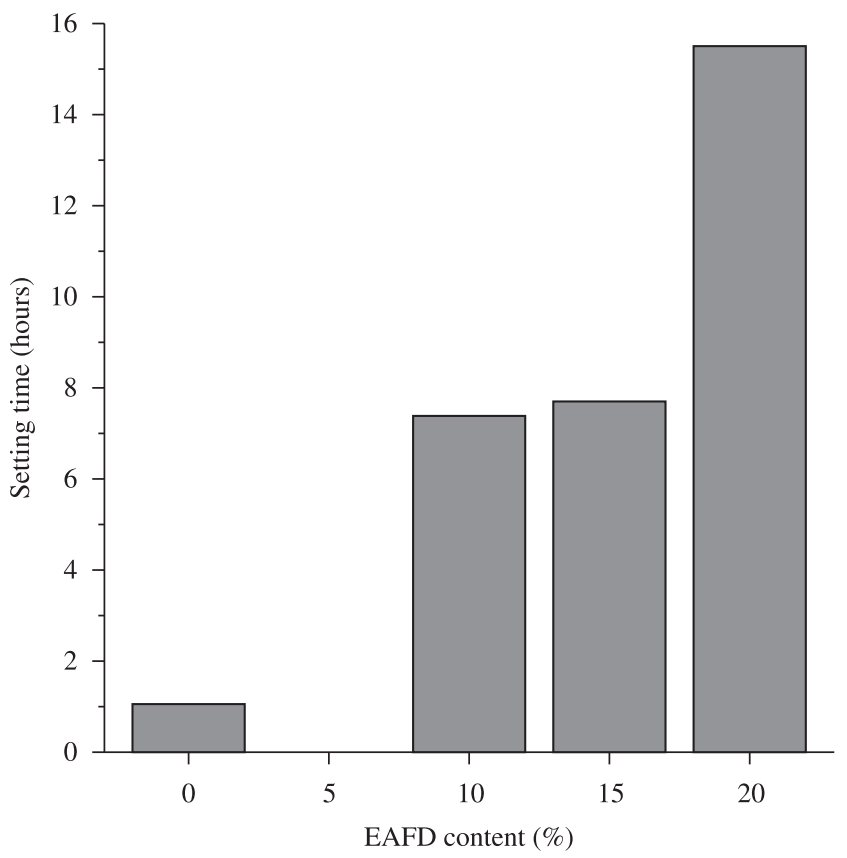

Figure 8. Effect of the EAFD content on the cement setting time.

Table 4. Liquid phase element content after the concrete sample acetic acid leaching (in $\mathrm{mg} . \mathrm{L}^{-1}$ ).

\begin{tabular}{lcccc}
\hline \multirow{2}{*}{ Elements } & Limit & \multicolumn{3}{c}{ EAFD content } \\
\cline { 2 - 5 } & $\left(\mathrm{mg} . \mathrm{L}^{-1}\right)$ & $10 \%$ & $15 \%$ & $20 \%$ \\
\hline Barium & 100.0 & 0.26 & 0.33 & 0.11 \\
Cadmium & 0.50 & $<0.002$ & $<0.002$ & $<0.002$ \\
Chromium & 5.0 & $<0.006$ & $<0.006$ & $<0.006$ \\
Lead & 5.0 & 0.40 & 0.06 & $<0.01$ \\
Silver & 5.0 & $<0.002$ & $<0.002$ & $<0.002$ \\
\hline
\end{tabular}

Table 5. Liquid phase element content after the concrete sample water solubilization (in $\mathrm{mg} \cdot \mathrm{L}^{-1}$ ).

\begin{tabular}{lcccc}
\hline Elements/ & Limit & \multicolumn{3}{c}{ EAFD content } \\
\cline { 3 - 5 }$\left(\mathrm{mg} . \mathrm{L}^{-1}\right)$ & $10 \%$ & $15 \%$ & $20 \%$ \\
\hline Aluminum & 0.20 & $0.93-1.19$ & $0.66-0.69$ & $0.57-0.59$ \\
Barium & 1.00 & $0.30-0.54$ & $0.66-0.78$ & $0.41-0.45$ \\
Cadmium & 0.01 & $<0.002$ & $<0.002$ & $<0.002$ \\
Chromium & 0.10 & $<0.006$ & $<0.006$ & $<0.006$ \\
Copper & 0.30 & $<0.003$ & 0.01 & 0.01 \\
Iron & 0.00 & $<0.006$ & $<0.006$ & $<0.006$ \\
Lead & 0.05 & $<0.01$ & 0.01 & $<0.01$ \\
Nitrate & 10.00 & $0.81-0.99$ & $0.85-0.93$ & $0.86-0.98$ \\
Silver & 0.05 & $<0.002$ & $<0.002$ & $<0.002$ \\
Sulfate & 400.00 & $16.75-17.13$ & $8.26-15.67$ & $15.78-27.73$ \\
Zinc & 5.00 & $<0.01$ & $0.021-0.023$ & $0.029-0.101$ \\
\hline
\end{tabular}

Standard NBR $10004^{20}$ can be observed. These results show that no other metal analyzed exceeded the levels proposed in the legislation to consider a material toxic except for aluminum, likely due to 
the dissociation of the calcium aluminate present in the clinker of Portland cement.

Therefore the results presented in Tables 4 and 5 indicate that concrete mixed with over 20 wt. (\%) EAFD can be classified as an inert material. The aluminum solubilization is due to the concrete matrix and does not causes environmental concerns. These observations corroborate the ability of concrete to stabilize potentially toxic elements such as cadmium and lead present in EAFD.

\subsection{Chloride penetration}

Figure 9 presents the chloride penetration curve in the cylindrical concrete samples for a 30 days immersion test. As can be seen there is a typical gradient driven process with high concentrations close to the surface and low concentrations at the center, which is described by equation 3 . It is observed that close to the cylinder center, between a radius of 30 and $70 \mathrm{~mm}$, the chloride concentration stabilizes at around $0.15 \%$, due the reduction in the chloride concentration gradient close to the center.

Furthermore, almost all the points of the chlorine penetration profile, when EAFD is added (EADF $15 \mathrm{wt}$. (\%)) to the concrete sample, are below the curve for concrete alone, except at point of $50 \mathrm{~mm}$ due to experimental difficulties to the analysis of low chloride content. The curves for 15 and 60 days of immersion, not shown here, have analogous behavior. These results indicate that the addition of EAFD increased the chloride ion penetration resistance, likely due to the micro-filling effect and the tendency for small particles to serve as nucleation sites for cement hydration.

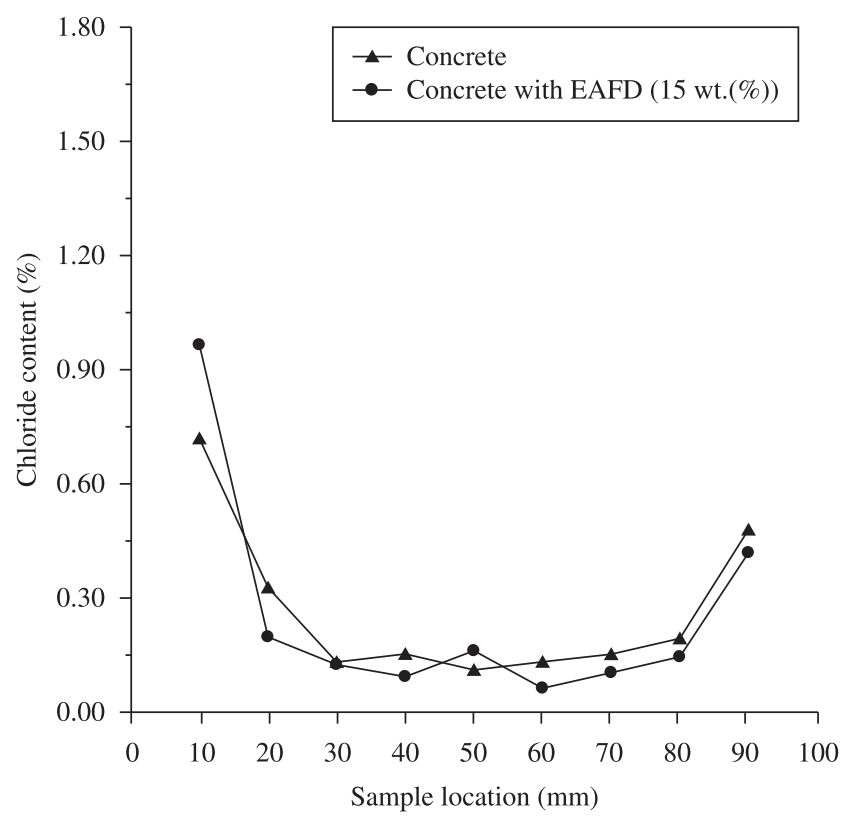

Figure 9. Chloride penetration profiled (percent of chloride per cement weight) in the cylindrical samples after 30 days immersion in $\mathrm{NaCl}$ solution.

Table 6. Average chloride content (in \%) at 30 to $40 \mathrm{~mm}$ of the cylindrical samples.

\begin{tabular}{ccc}
\hline $\begin{array}{c}\text { Immersion time } \\
\text { (days) }\end{array}$ & Concrete & $\begin{array}{c}\text { Concrete with } \\
\text { EAFD }\end{array}$ \\
\hline 15 & 0.145 & 0.098 \\
30 & 0.147 & 0.088 \\
60 & 0.104 & 0.098 \\
\hline
\end{tabular}

Table 6 shows the average chloride content of the samples at 30 to $40 \mathrm{~mm}$ of the cylindrical samples, which are estimated as the average value of the chloride content at 30, 40, 60 and $70 \mathrm{~mm}$. Note that these results indicate that in all cases the addition of EAFD (15 wt. (\%)) significantly reduces the average chloride content.

The thickness of a reinforced concrete layer must be higher than 30 to $40 \mathrm{~mm}$, therefore the addition of EAFD may prevent pitting corrosion caused by the presence of chloride. In accordance with the Brazilian standard ${ }^{21}$ the chloride concentration must be below 0.4 wt. (\%) to prevent corrosion in reinforced concrete. The results presented in this work show that the chloride concentration at $30-40 \mathrm{~mm}$ is lower than this value.

\section{Conclusions}

This study evaluated the effect of the addition of 10,15 and 20 wt. (\%) EAFD on the mechanical properties and chloride penetration of Portland cement. It was found that the addition of EAFD caused a significant delay in the setting time of concrete samples. In addition, the axial compressive strength of concrete samples increased with the addition of EAFD. The tensile strength of the concrete with added EAFD is similar or better when compared to a reference concrete sample. Leaching tests show that no other metal analyzed exceeded the levels proposed in the Brazilian standards as toxic except for aluminum, which seems to come from the dissociation of the calcium aluminate present in the Portland cement. The presence of EAFD (15 wt. (\%)) in the cement indicate a decrease in chloride penetration in the concrete samples.

\section{Acknowledgments}

This research was supported by the Conselho Nacional de Desenvolvimento Científico e Tecnológico (CNPq, Brazil).

\section{References}

1. Hagni AM, Hagni RD and Demars C. Mineralogical characteristics of electric arc furnace dust. Journal of the Minerals (JOM). 1991; 43:28-30.

2. Sofilié T, Rastovcan-Mioc A, Cerjan-Stefanovié S, Novosel-Radovié V and Jenko M. Characterization of steel mill electric-arc furnace dust. Journal of Hazardous Materials. 2004; B109:59-79.

3. da Silva Machado JGM, Brehm FA, Moraes CAM, dos Santos CA and Vilela ACF. Characterization Study of Electric Arc Furnace Dust Phases. Materials Research. 2006; 9(1):41-45.

4. Al-Zaid RZ, Al-Sugair FH and Al-Negheimish AI. Investigation of potential uses of electric-arc furnace dust (EAFD) in concrete. Cement and Concrete Research. 1997; 27:267-278.

5. Mikhail SA, Turcotte AM and Aota J. Thermoanalytical study of EAF dust and its vitrification product. Thermochimica Acta. 1996; 287:71-79.

6. Pelino M, Karamanov A, Pisciella P, Crisucci S and Zonetti D. Vitrification of electric arc furnace dusts. Waste Management, 2002; 22:945-949.

7. de Vargas AS, Masuero AB and Vilela ACF. Investigation on the use of electric-arc furnace dust (EAFD) in Pozzolan-modified Portland cement I (MP) pastes. Cement and Concrete Research. 2006; 36:1833-1841.

8. Laforest $\mathrm{G}$ and Duchesne J. Investigation of stabilization/solidification for treatment of electric arc furnace dust: dynamic leaching of monolithic specimens. Cement and Concrete Research. 2007; 37:1639-1646.

9. Hamilton IW and Sammes NM. Encapsulation of steel foundry bag house dusts in cement mortar. Cement and Concrete Research. 1999; 29:55-61.

10. Crank J. The Mathematics of Diffusion. Oxford University Press; 1964.

11. Tumidajski PJ, Chan GW, Feldman RF and Strathdee G. A BoltzmannMatano analysis of chloride diffusion. Cement and Concrete Resarch. 1995; 25:1556-1566. 
12. ASTM. Standard test method for splitting tensile strength of cylindrical concrete specimens (C496-90). Philadelphia, PA: ASTM; 1993; Sect. 4, vol. 04.02., p. 269-272. Annual book of ASTM Standards.

13. Mendham J, Denney RC, Barnes JD and Thomas MJK. Vogel's Quantitative Chemical Analysis. $6^{\text {th }}$ ed. Prentice Hall; 2000.

14. Brazilian Standard NBR 10005. Leaching test-procedures. $2^{\text {nd }}$ ed. Rio de Janeiro; 2004. In Portuguese.

15. Brazilian Standard NBR 10006. Waste solubilization. $2^{\text {nd }}$ ed. Rio de Janeiro; 2004. In Portuguese.

16. Brazilian Standard NBR NM65/2003: Portland cement: Determination of the setting time. Rio de Janeiro; 2003. In Portuguese.
17. Maslehuddin M, Awan FR, Shameem M, Ibrahim M and Ali MR. Effect of electric arc furnace dust on the properties of OPC and blended cement concretes. Construction and Building Materials. in press. DOI10.1016/j. conbuildmat.2010.06.024.

18. Lea FM. The Chemistry of Cement and Concrete. $3^{\text {rd }}$ ed. New York; 1970.

19. Taylor HFW. Cement Chemistry. New York: Academic Press; 1990.

20. Brazilian Standard NBR 10004. Solid waste-classification. $2^{\text {nd }}$ ed. Rio de Janeiro; 2004. In Portuguese.

21. Brazilian Standard NBR7211/05: Aggregated for concrete. Rio de Janeiro; 2005. In Portuguese. 